\title{
A morphology-based assay platform for neuroepithelial-like cells differentiated from human pluripotent stem cells
}

\author{
MIKA SUGA ${ }^{1}$, HIROAKI KII², NAOKO UEDA ${ }^{1}$, YU-JUNG LIU'1', TAKAKO NAKANO ${ }^{1}$, TOMORO DAN², \\ TAKAYUKI UOZUMI2, YASUJIRO KIYOTA² and MIHO K. FURUE*,1,2 \\ ${ }^{1}$ Laboratory of Stem Cell Cultures, National Institutes of Biomedical Innovation, Health and Nutrition, Osaka and \\ ${ }^{2}$ Nikon Corporation, Tokyo, Japan
}

\begin{abstract}
Cell morphology is recognized as an important hallmark of neural cells. During the differentiation of human pluripotent stem cells (hPSCs) into neural cells, cell morphology changes dynamically. Therefore, characterization of the morphology of cells during this period is important to improve our understanding of the differentiation and development of neural cells. General methods for the directed induction of hPSCs include the steps of multi-cellular aggregation or high-density cell culture, particularly at the early phase of neural differentiation, and therefore, the morphology of each differentiating cell is difficult to recognize. Here, we have developed a new method for the directed differentiation of neuroepithelial-like cells (NELCs) from hPSCs at a low cell density in an adherent monolayer culture, as well as an image-processing algorithm to evaluate the cell morphology of differentiating NELCs, in order to follow cell morphology during the differentiation of hPSCs into NELCs. Using these methods, the morphological transition of differentiating cells was observed in real time using phase contrast imaging and then quantified. Because cell morphology is also considered an inherent biological marker of neural cells cultured in vitro, this method is potentially useful to study the mechanisms underlying neural cell differentiation.
\end{abstract}

KEY WORDS: differentiation, neuroepithelial-like cell, monolayer culture, albumin-free defined culture medium

\section{Introduction}

Induced neural stem cells derived from human pluripotent stem cells (hPSCs), including human embryonic stem cells (hESCs) (Thomson et al., 1998) and human induced pluripotent stem cells (hiPSCs) (Takahashi et al., 2007), represent a promising new tool enabling improvements in our understanding of the mechanisms of human brain development, neural differentiation, and brain diseases. Because most neural cells, which are divided into neurons and glial cells, have the fundamental functions of transmitting signals and communicating with each other through their many processes extending from soma, the morphology of neural cells is recognized as an important hallmark and differs from other types of cells (Parekh and Ascoli, 2013). Neural stem cells also display a characteristic morphology and dynamically change their morphology during cell differentiation. In vertebrate embryogenesis, neuroepithelial cells function as neural stem cells which eventually differentiate to multiple types of neurons and glia in the brain and the spinal cord. Neural induction is initialized by cell fate specification of ectoderm germ layer towards neuroepithelial cells when signaling molecules are released from organizer cells at gastrula stage (Fukui and Asashima, 1994, Furue and Asashima, 2004). In this process, bone morphogenetic protein (BMP) signaling inhibition and fibroblast growth factor (FGF) signaling activation are important for neural cell fate commitment. Methods for in vitro neural induction from hPSCs have been developed by following these signaling pathway control in embryos. However, general methods for inducing the differentiation of neural cells from $\mathrm{hP}$ SCs include multi-cellular aggregation steps (embryonic bodies or neurospheres) or the use of a high cell density (Chambers et al., 2009, Kelava and Lancaster, 2016). These conditions hamper to

\footnotetext{
Abbreviations used in this paper: BMP, bone morphogenetic protein; FGF-2, fibroblast growth factor-2; hESC, human embryonic stem cell; hiPSC, human induced pluripotent stem cell; hPSC, human pluripotent stem cell; NELC, neuroepithelial-like cell.
}

*Address correspondence to: Miho K. Furue. Laboratory of Stem Cell Cultures, National Institutes of Biomedical Innovation, Health and Nutrition, 7-6-8, SaitoAsagi, Ibaraki, Osaka 567-0085, Japan. E-mail: mkfurue@gmail.com - (iD) https://orcid.org/0000-0001-5032-9953

Supplementary Material (two videos, two tables and 7 figures) for this paper is available at: https://doi.org/10.1387/ijdb.180161mf

Submitted: 2 February, 2018. Accepted: 6 June, 2018. Edited by: Makoto Asashima

ISSN: Online 1696-3547, Print 0214-6282

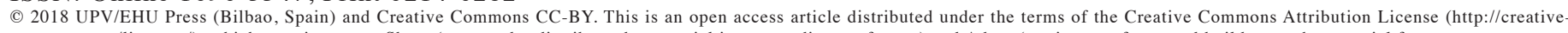

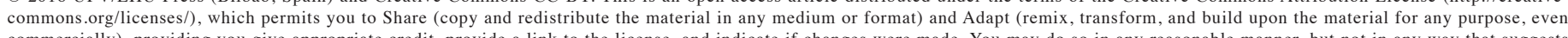

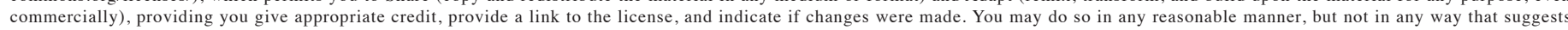
the licensor endorses you or your use. Printed in Spain 
A

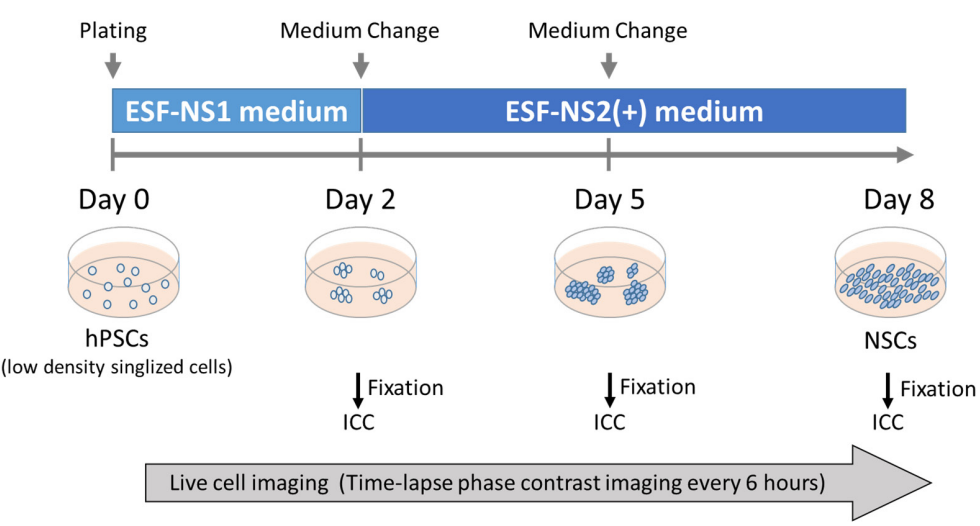

B Tic

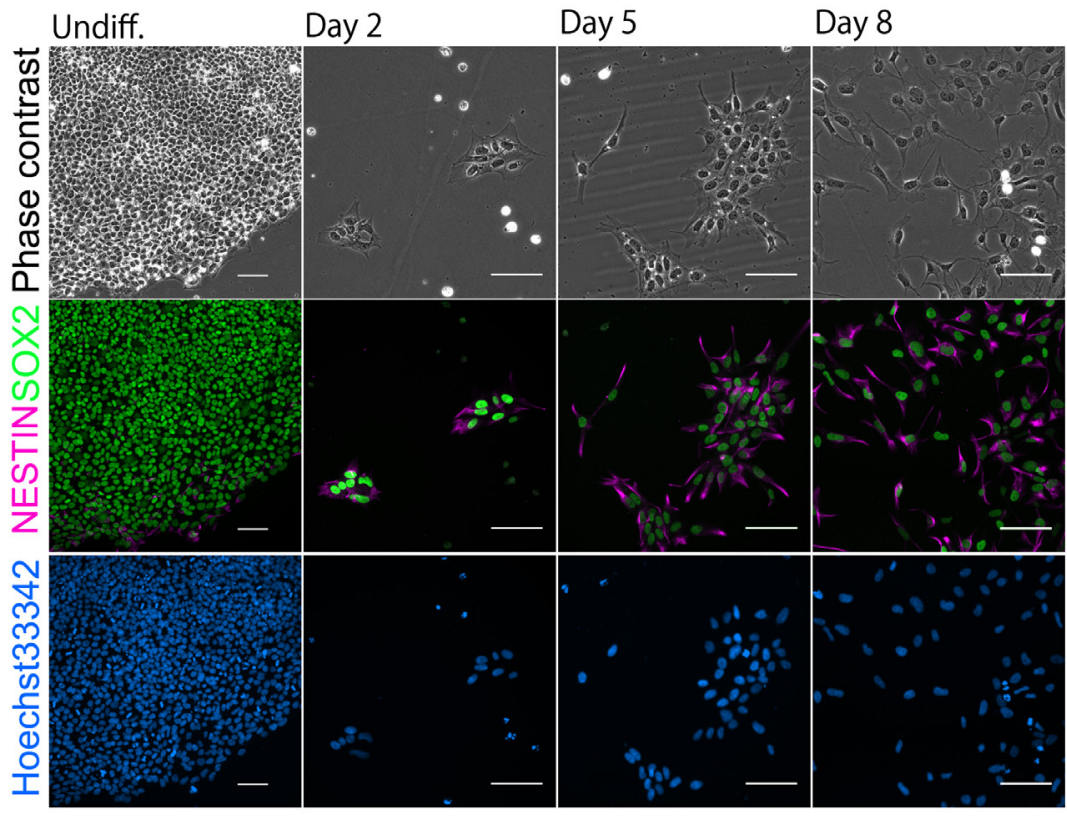

C H9 Undiff.

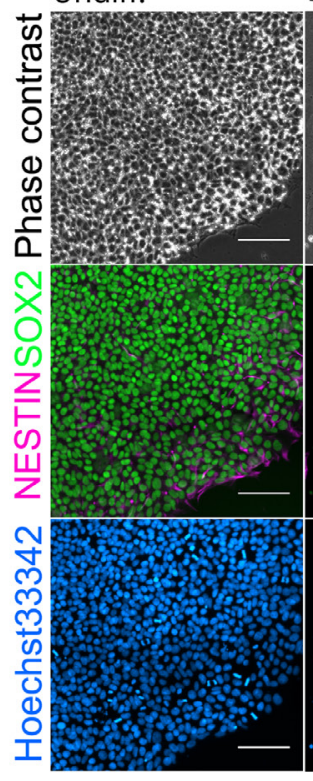

Day 2

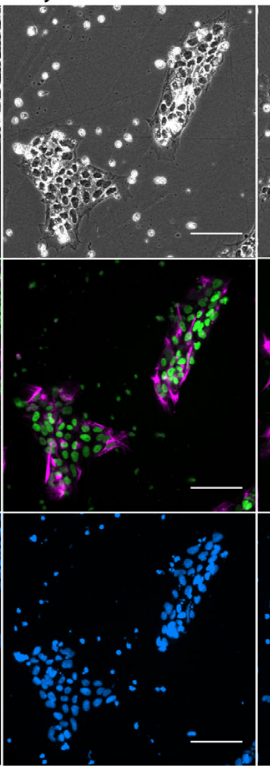

Day 5

Day 8

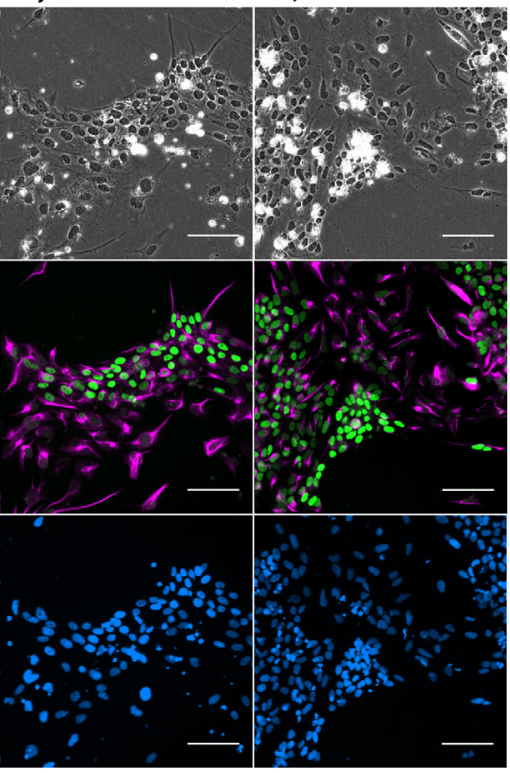

monitor changes in cell morphology during differentiation. Further, these high cell density in vitro conditions are not suitable to analyze the effects of exogenous growth factors because autocrine/paracrine signaling factors are abundantly compensated from the cells themselves. To address these two issues, we developed a new neural induction method under low cell density condition.

We previously reported several culture methods for maintaining undifferentiated neuroectodermal cancer cells, mouse embryonic stem cells, and hPSCs in growth factor-defined serum-free culture medium, in which the effects of exogenous factors is able to be analyzed without the confounding influences of undefined components (Furue et al., 2005, Furue et al., 1994, Furue et al., 2008, Na et al., 2010). In our defined conditions, a kinase inhibitor library was screened to identify fibroblast growth factor (FGF)-2-related molecular mechanisms regulating the self-renewal of hPSCs (Kinehara et al., 2013). The protein kinase C (PKC)/GSK-3 $\beta$ inhibitor GF109203X and mitogenactivated protein kinase/ERK-1/2 kinase (MEK1/2) inhibitor U0126 promote the self-renewal of hPSCs by activating both the activin A and FGF-2 signaling pathways (Kinehara et al., 2013). In contrast, the bone morphogenetic protein (BMP) antagonist Noggin and the activin/Nodal/TGF- $\beta$ inhibitor SB431542 are generally used to induce the differentiation of hPSCs into neural cells in KSR and/or Matrigel-containing culture conditions (Chambers et al., 2009, Kelava and Lancaster, 2016).

Recently, the combination of image analysis methods with computational data processing techniques has facilitated the evaluation of cellular status based on non-labeled images (Maddah et al., 2014). We previously reported a non-invasive morphological analysis of hPSCs based on multiple morphological parameters measured from cell images (Kato et al., 2016). Non-invasive time-lapse imaging can calculate the numbers and growth rate of hPSCs (Suga et al., 2015). The classification based on cell biological features, such as marker profiles or gene expression,

Fig. 1. Neuroepithelial-like cell (NELC) induction from human pluripotent stem cells (hPSCs). (A) Schematic of the NELC induction method established in this study. After plating at a low cell density, cells were cultured for 8 days. The medium was replaced on days 2 and 5 . For immunostaining, the induced cells were fixed on days 2, 5 and 8. Live-cell morphology was monitored by capturing images of the cells every 6 hours throughout NELC induction, starting 6 hours after plating. (B,C) Morphology and the expression of NESTIN and SOX2 in cells differentiated from Tic hiPSCS (B) and H9 hESCs (C) during NELC induction. Upper row: representative phase contrast images of an undifferentiated hPSC colony (Undiff.) and the cells at days 2, 5, and 8 of NELC induction. Middle row: representative images of immunostaining with antibodies against NESTIN (magenta) and SOX2 (green). Lower row: representative images of Hoechst 33342 (b/ue) nuclear staining. Bar, $50 \mu \mathrm{m}$. 
determined using invasive methods are comparable to classification derived from a non-invasive morphological analysis (Kato et al., 2016, Suga et al., 2015).

Based on these findings, in the present study, we developed a new minimum essential culture condition for neuroepithelial-like cell (NELC) induction from hPSCs in an adherent monolayer culture at a low cell density to monitor the morphology of hPSCs as they differentiated into NELCs and an image-processing algorithm to evaluate the cell morphology. Under this condition, cell morphology and dynamics were observed during NELC induction in low cell density monolayer cultures, suggesting differentiation mechanisms.

\section{Results}

\section{Induction medium for neuroepithelial-like stem cells}

An adherent monolayer differentiation protocol at a low cell density would be suitable for monitoring and analyzing cell morphology during the differentiation of hPSCs into NELCs. Therefore, we developed a minimum essential medium, designated ESF-NS medium for NELC induction from hPSCs under low-cell-density monolayer culture conditions. A human lung fibroblast MRC-5-derived hiPSC line Tic (Nagata et al., 2009) and an hESC line H9 (Thomson et al., 1998) were serially cultured in a feeder-free, Xeno-free defined hESF-FX medium (PCT/JP2011/004691, Yanagihara et al., 2016), which we modified from hESF9 medium (Furue et al., 2008) to maintain an undifferentiated state of hPSCs and develop a reproducible differentiation process in optimized NELC induction medium. Sets of supplements in hESF-FX medium were optimized as the required minimum essential components (Fig. S1), showing that a set of sodium selenite and human recombinant insulin was minimally required for cell survival in the presence of human recombinant FGF-2 and L-ascorbic acid phosphate magnesium salt. Then, dissociated single undifferentiated hPSCs were plated on tissue culture plates coated with polyL-lysine, bovine collagen type IV, bovine fibronectin, poly-L-lysine and bovine fibronectin, or mouse laminin, and cultured in mESF basal medium (Furue et al., 2005, Yanagihara et al., 2016) supplemented with

Fig. 2. Gene expression during NELC induction. Tic hiPSCs were differentiated into NELCs using the method described in Fig. 1A. Representative qRT-PCR results for gene expression in the cells on days 5 (yellow), 7 (cyan), and 8 (navy) are shown. GAPDH was used as an internal control. Relative gene expression was normalized to the expression in undifferentiated Tic hiPSCS cultured in hESF-FX (mean \pm $S D, n=3)$.
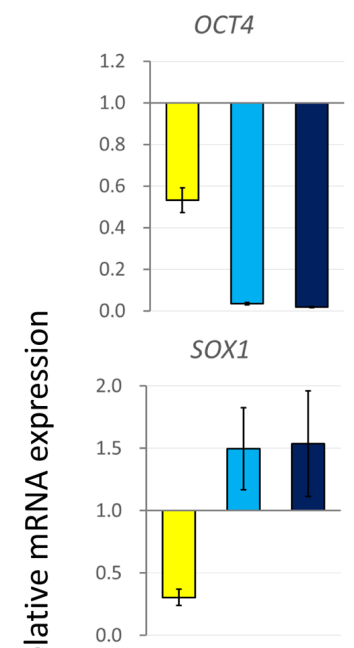

PAX3

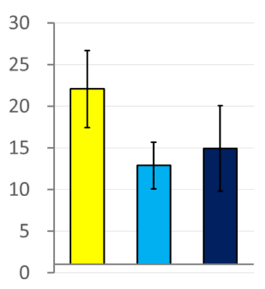

Day 5

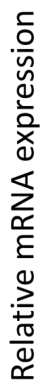

$20 \mathrm{ng} / \mathrm{ml}$ sodium selenite, $10 \mu \mathrm{g} / \mathrm{ml}$ human recombinant insulin, 5 $\mathrm{ng} / \mathrm{ml}$ human recombinant FGF-2, and $0.1 \mathrm{mg} / \mathrm{ml} \mathrm{L}$-ascorbic acid phosphate magnesium salt in the absence of human transferrin, oleic acid conjugated bovine albumin or recombinant albumin. When cells were plated on the dishes coated with poly-L-lysine and fibronectin, the cells were viable and adhered without the addition of the ROCK inhibitor to this medium (Figs. 1B and S2). This minimal essential medium was named ESF-NS1.

Signaling networks involving PI3K, MAPK/ERK, PKC, BMP, TGF- $\beta$ /activin/Nodal, and Wnt determine the cell fate of hPSCs (Chambers et al., 2009, Dalton, 2013, Hayashi et al., 2010, Kinehara et al., 2013, Na et al., 2010, Vallier et al., 2009). To determine the effect of the PI3K inhibitor LY294002 (Vlahos et al., 1994), the MEK inhibitor U0126 (Favata et al., 1998), the BMP inhibitor Noggin (Valenzuela et al., 1995), the TGF- $\beta$ /activin/Nodal inhibitor SB431542 (Inman, 2002) and the PKC inhibitor (a potential GSK-3 $\beta$ inhibitor) GF 109203X (Hers et al., 1999) on cell viability and neural conversion in the adherent monolayer culture, the cells cultured for two days in ESF-NS1 were treated with various combinations of these 5 inhibitors in ESF-NS1 medium without ascorbic acid and with $100 \mathrm{ng} / \mathrm{ml} \mathrm{FGF-2} \mathrm{(Fig.} \mathrm{S3).} \mathrm{The} \mathrm{addition}$ of LY294002 or U0126 decreased cell numbers. When Noggin was added to the medium, the relative number of OCT-4-positive cells increased. The addition of GF 109203X did not affect the cell number, but it reduced the number of OCT-4-positive cells. When GF 109203X was added along with Noggin and SB431542, the number of OCT-4-positive cells was further reduced, and the cell number was increased slightly. Based on these results, inhibition of the BMP, TGF- $\beta$ /activin/Nodal, and GSK-3 $\beta$ signaling pathways are sufficient for cell survival/proliferation and escape from the undifferentiated state. The ratio of NESTIN-positive cells to total viable cells revealed that GF 109203X induced neural differentia-
NANOG

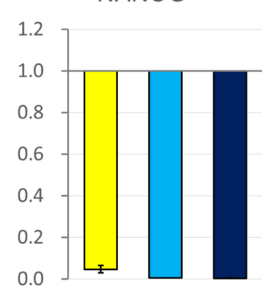

SOX9

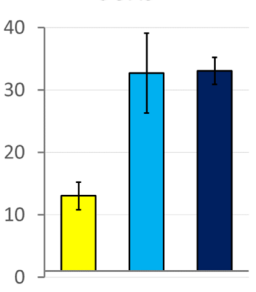

MSX1

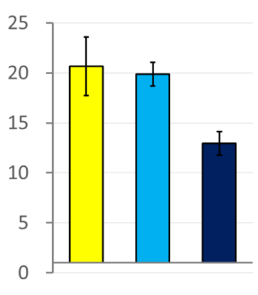

Day 8

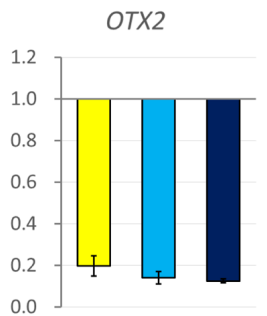

PAX6

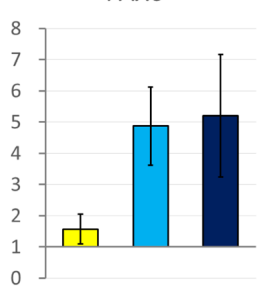

FOXD3

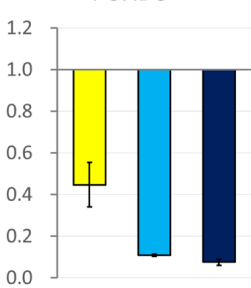

0.0

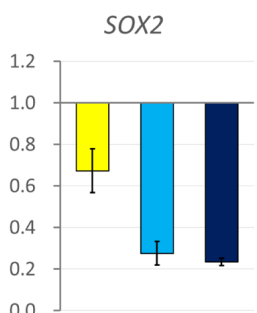

ASCL1

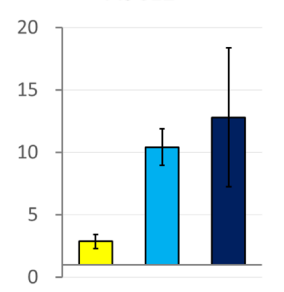

sox10

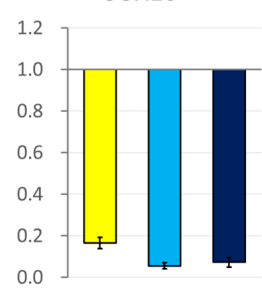

0.0

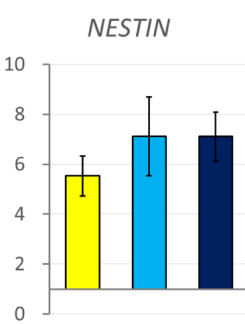

TUJ1

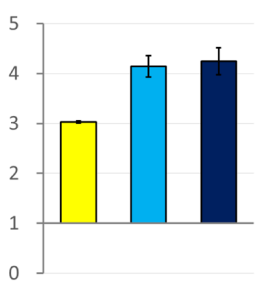

$T$

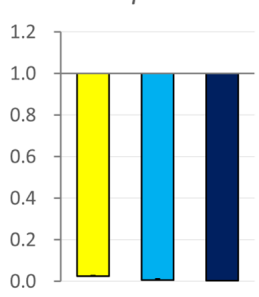

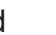


tion (Fig. S3C).

The use of a high dosage of FGF-2 $(100 \mathrm{ng} / \mathrm{ml})$ is costly. Heparan sulfate proteoglycans and heparin are well known cofactors that enhance the activity of FGF-2 (Flaumenhaft et al., 1990, Furue et al., 2008). We tested the effects of the addition of heparan sulfate to the medium and found that the induction of differentiation with heparan sulfate and a lower concentration of FGF-2 $(10 \mathrm{ng} / \mathrm{ml})$ produced cells that were similar to those induced with a high concentration of FGF-2 (100 ng/ml) (Fig. S3D). Based on these results, we established the NELC induction medium as mESF basal medium supplemented with $10 \mu \mathrm{g} / \mathrm{ml}$ human recombinant insulin, $10 \mathrm{ng} / \mathrm{ml}$ sodium selenite, $100 \mathrm{ng} / \mathrm{ml}$ heparan sulfate sodium salt, $10 \mathrm{ng} / \mathrm{ml}$ human recombinant FGF-2, $2.5 \mu \mathrm{M}$ GF 109203X, and $10 \mu \mathrm{M}$ SB431542. Undifferentiated hPSCs maintained in hESFFX medium were dissociated into single cells by treatment with Accutase ${ }^{\circledR}$ and seeded in ESF-NS1 medium on a 6-well tissue culture plate coated with poly-L-lysine and bovine fibronectin at an appropriate cell density for each cell line (Tic: 2,400 cells $/ \mathrm{cm}^{2}$; $\mathrm{H} 9: 6,000$ cells $/ \mathrm{cm}^{2}$ ). Dissociation into single cells and seeding at appropriate cell density which requires skillful techniques was the critical process for the differentiation in our culture conditions (Fig. S3, F and G). However, stable differentiation was obtained by the addition of Noggin even with unskillful techniques. Dorsomorphin $(600 \mathrm{nM})$ was replaced with Noggin, which is also costly. Finally, the protocol consisted of 2 steps: plating dissociated hPSCs in plating medium (ESF-NS1) on a culture plate coated with polyL-lysine and bovine fibronectin and replacing the medium with NELC induction medium, designated ESF-NS2(+), on day 2 and refreshing it on day 5 (Fig. 1A).

\section{Expression of earlyectodermal lineage markers in the induced neuroepithelial-like cellS (NELCS)}

Using this protocol, undifferentiated Tic and $\mathrm{H} 9$ cells seeded at a low cell density in monolayer cultures were differentiated into NELCs (Fig. 1B and C). Phase contrast images displayed small assemblies of the cells on day 2 . Relatively large assemblies of cells with protrusions were observed on day 5 . From day 5 to day 8 , the induced cells started to disassemble and migrate out from the assemblies. According to the immunocytochemistry, these cells expressed the neural stem cell marker proteins NESTIN, SOX2, SOX1, and PAX6 (Figs. 1B, 1C, and S3). Another hiPSC line, iPS DF 19-9-7T cells, were serially cultured in mTeSR1 medium (Yu et al., 2009) and treated using the same protocol described above to test the utility of our NELC induction method. The morphology of iPS DF 19-9-7T cells changed to an NELClike morphology, indicating that iPS DF 19-9-7T cells maintained in mTeSR1 medium differentiated into NELCs using the same protocol (Fig. S2E).

Gene expression was monitored in the cells on days 5, 7, and 8 of NELC induction using qRT-PCR to examine the differentiation process during NELC induction (Fig. 2). The master pluripotency regulator genes OCT-4 and NANOG were significantly downregulated in the induced NELCs on days 7 and 8 . An undifferentiated stem cell marker, SOX2, and an early neural ectodermal linage marker, OTX2, were down-regulated but still expressed at relatively high levels. The NELC induction condition favored the expression of neural ectoderm- and neural cell-associated markers, including NESTIN, SOX1, SOX9, PAX6, ASCL1, and TUJ1. SOX9, which regulates development both in the central nervous

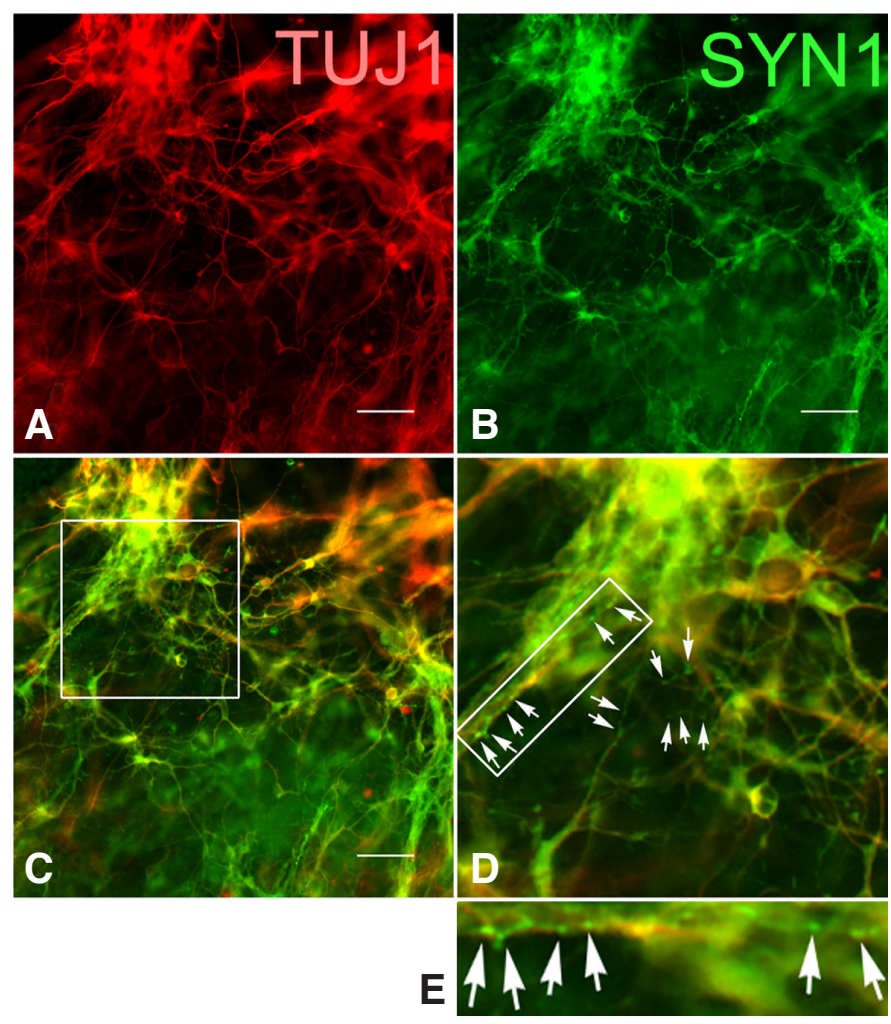

Fig. 3. Potential of the induced NELCs to differentiate into neurons. To confirm whether the induced NELCS have differentiation potential into neurons, the induced NELCs were further differentiated into neurons in the conventional culture conditions. Fixed cells were stained for (A) tubulin $\beta 3$ (TUJ1, red) and (B) synapsin 1 (SYN1, green). (C) Merge of the images in $(A, B)$. (D) Magnified image of the white rectangular region in $C$. (E) Magnified image of the white rectangular region in $D$. Arrows indicate representative SYN1-positive synaptic puncta along TUJ1-positive neurites. Bar, $100 \mu \mathrm{m}$.

system and in the neural crest, was expressed at a high level in the induced NELCs. PAX3 and MSX1, both known as neural fold markers and early neural crest markers, were expressed at high levels on day 5 but were slightly down-regulated on days 7 and 8 . The neural crest stem cell markers FOXD3 and SOX10 were not up-regulated. The expression of the gene encoding the mesoderm marker $T$ (brachyury transcription factor) was not detectable. SOX17 and FOXA2, which are endoderm markers and transcription factors, were detected in the induced NELCs, but their expression was quite low compared with the induced definitive endoderm cells (Fig. S4). Taken together with the results of the immunostaining analysis (Figs. 1 and S3), the induced NELCs exhibited characteristics of early ectodermal and neuroepithelial cells but not neural crest, mesodermal or endodermal cells.

\section{Neuronal differentiation potential of the induced NELCs}

Next, we confirmed whether the induced NELCs displayed the potential for further neuronal differentiation. The induced NELCs were harvested on day 8 and plated on laminin-coated culture plates. Their media was replaced with the conventional neuronal differentiation medium 2 days after re-plating, and then they were cultured for 18 additional days. A large number of neurons with long, TUJ1-positive neurites and synapsin 1 (SYN1)-positive synaptic puncta were observed by immunostaining (Figs. 3 and 

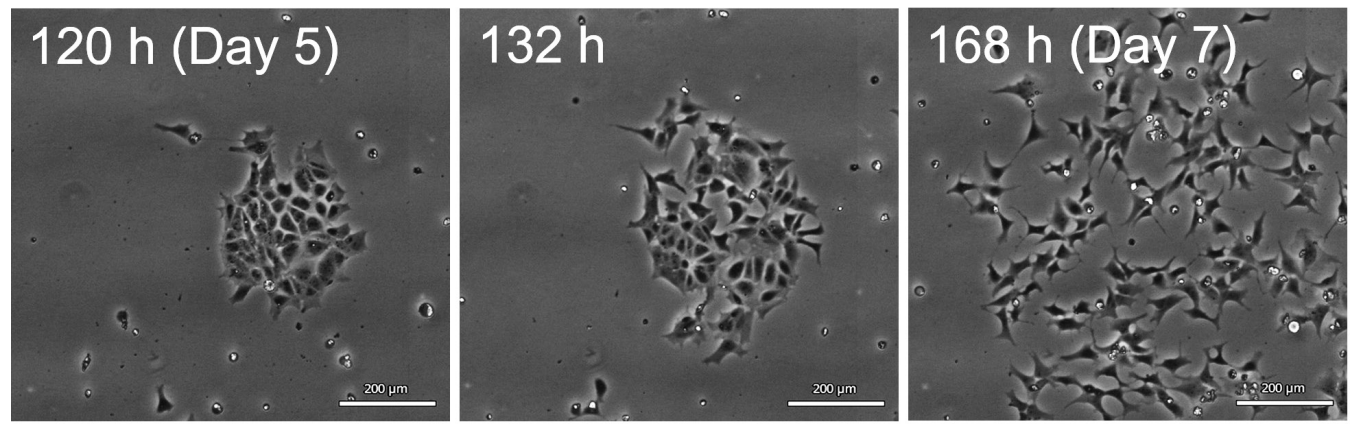

Fig. 4. Morphological transition of the cells during NELC induction. Time-lapse phase contrast images were obtained during NELC induction from Tic hiPSCs using the method described in Fig. 1A. Images at the respective time points are shown. Time-lapse im ages of the same fields are shown as SupplementaryVideo S1B. Bar, 200 um

Lamouille et al., 2014). Then, these EMT-related gene expression was determined in the cells on days 5,7 , and 8 (Fig. 5). E-CAD in the cells on day 5 was comparable with that of undifferentiated hPSCs but decreased on day 7 and 8 while VIMENTIN expression gradually increased. On days 5, 7, and 8, expression level of $N$ $C A D$ which is known to stimulate migration (Derycke and Bracke, 2004) increased eight-fold or more than that of undifferentiated hPSCs. Fibronectin 1 (FN1) expression was slightly up-regulated on days 7 and 8 compared with that in undifferentiated hPSCs. SLUG expression was comparatively higher on day 7 compared with that in undifferentiated hPSCs and then decreased (Fig. 5). The gene expression change of SNAIL was small. Only on day 7, the expression level of SNAIL seemed slightly higher than that on undifferentiated state cells or day 5 cells, but the difference was not significant (Fig.5). Because GF 109203X inhibits up-regulation of EGR1 function, upstream of SNAIL in EMT (Kinehara et al., 2014), SNAIL expression might be inhibited in our culture conditions. On the other hand, TWIST expression level on day 5 was increased 37.8 \pm 2.9 fold higher than that in undifferentiated state, and remained at a high level on days 7 and 8 (Fig. 5). By contrast, cell numbers were not increased on day 7 according to the live-cell imaging data (Fig. trusions by day 7. Based on this finding, the epithelial-mesenchymat transition (EMT) occurred during NELC induction. EMT is judged by loss of epithelial cadherin $(E-C A D)$ expression and the expression of VIMENTIN, FIBRONECTIN and neural cadherin $(N-C A D)$. The switch in cell differentiation is mediated by key transcription factors, including SNAIL, SLUG, TWIST (Derycke and Bracke, 2004,

Fig. 5. EMT-related gene expression during the cell morphology transition. Tic hiPSCs were differentiated into NELCs using the method described in Fig. 1A. Representative qRT-PCR results for gene expression in the cells on days 5 (yellow), 7 (cyan), and 8 (navy) are shown. GAPDH was used as an internal control. Relative gene expression was normalized to the expression in undifferentiated Tic hiPSCs cultured in hESF-FX (mean \pm $S D, n=3)$.

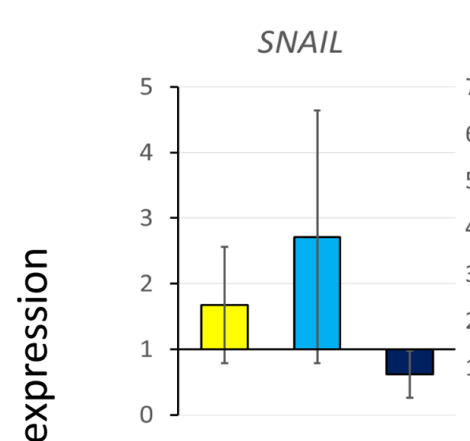

E-CAD

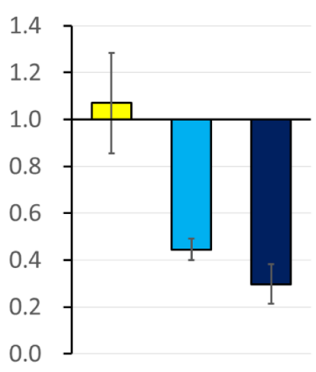

Day $5 \quad \square$ Day $7 \quad \square$ Day 8

$\frac{\sum}{\frac{1}{\varepsilon}}$

SLUG

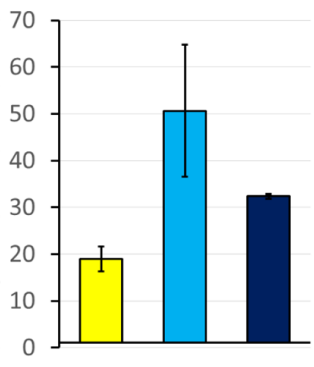

$N-C A D$

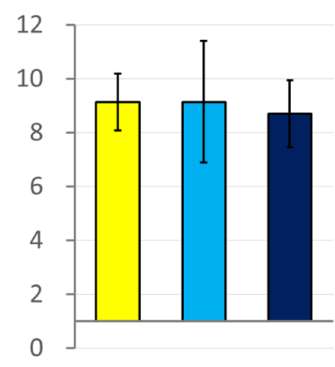

TWIST

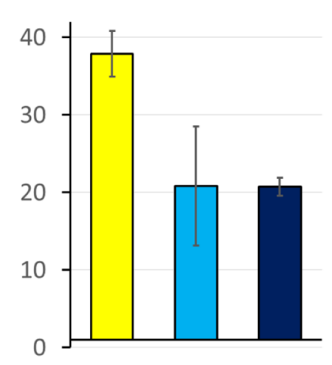

MKI67

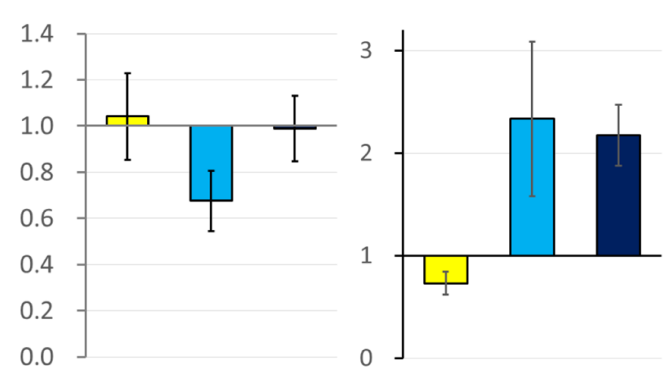

VIMENTIN

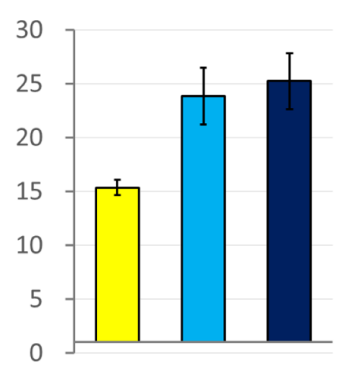

FN1 
4 and Video S1). The expression of the proliferation marker MKI67 decreased on day 7 (Fig. 5). Thus, changes in cellular phenomena and gene expression are temporally coordinated.

\section{Image analyses of cell morphology during differentiation from hPSCs into NELCs}

We developed an image-processing algorithm to classify cell morphology and measure each classified area in these phase

A

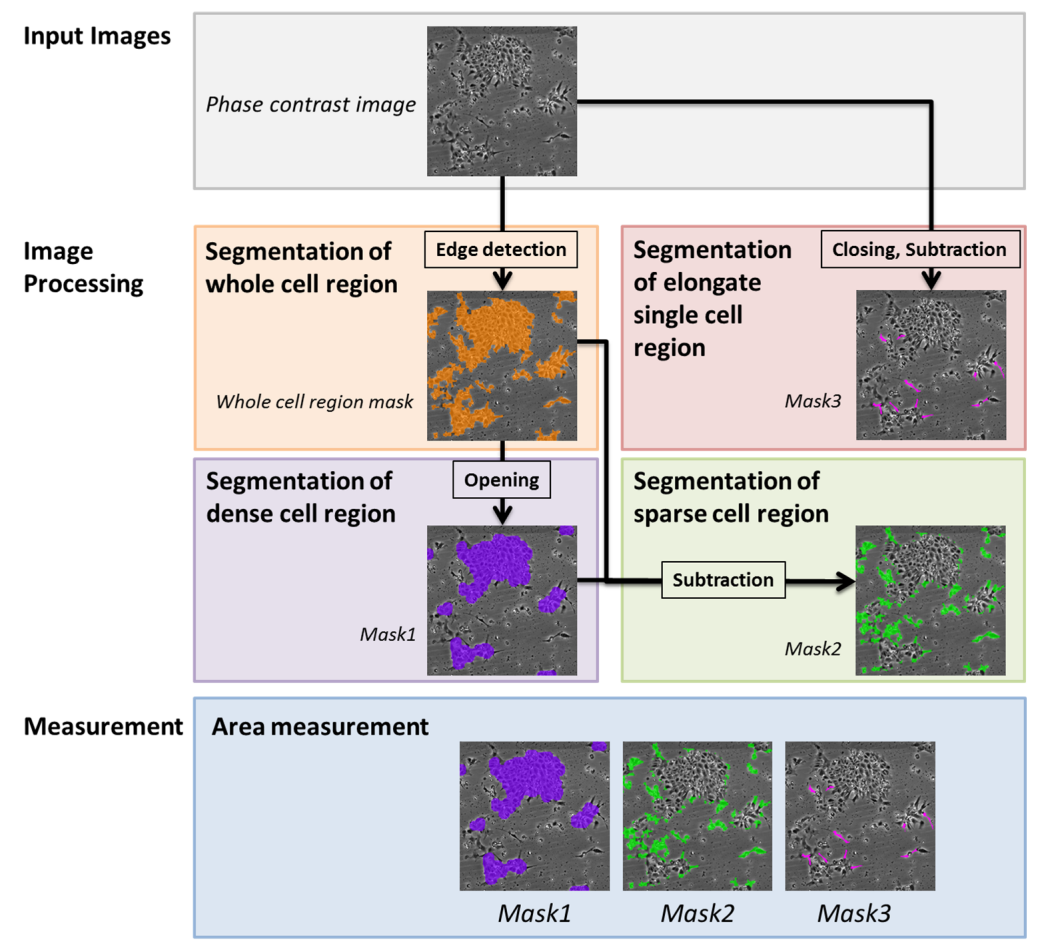

B

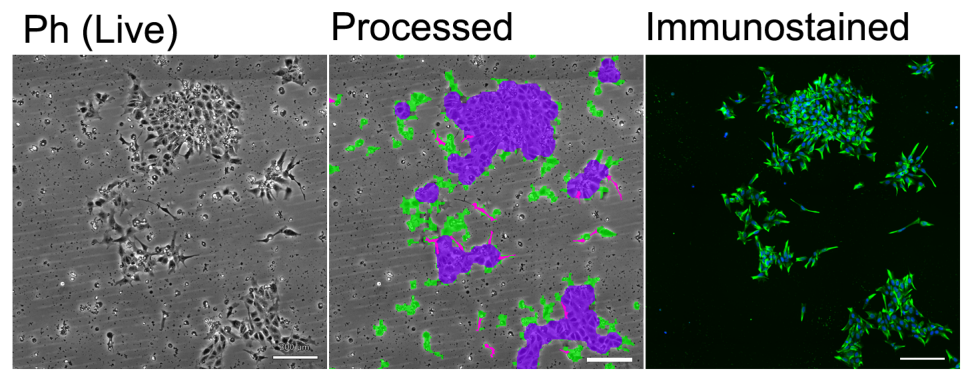

C

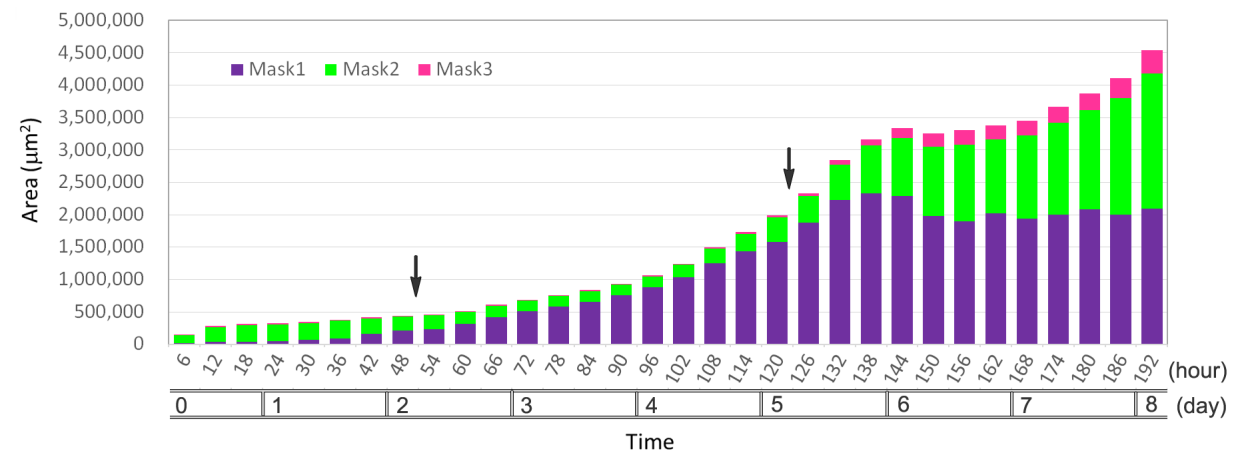

contrast images (Fig. 6A and Table S2). The phase contrast images were processed to classify the cell coverage area into three types, Mask1, Mask2, and Mask3, according to cell morphology, after which the classified area was measured. Mask1 represented a densely populated region of cells, Mask2 represented a sparsely populated region of cells, and Mask3 represented a region containing elongated single cells (Fig. 6B). Cells detected in Mask2 and Mask3 expressed high NESTIN levels by immunostaining (Fig. 6B). Area of Mask1 increased from days 0 to 5 , but on day 6 , the area of the Mask1 region decreased. The areas of Mask 2 and Mask3 were almost increased with days in culture (Figs. 6C, S7 and Video S2). According to the analysis of time-lapse images, the cell morphology transition and dynamic differentiation occurred from days 5 to 6 during NELC induction without the need to stop the culture or damage cells.

\section{Discussion}

In the present study, we developed a method for NELC induction from hPSCs at a low cell density using a fully defined medium to monitor cell morphology during NELC induction in an adherent monolayer culture condition. Because the cell density was quite low, individual cells could be recognized and tracked during NELC induction without stopping cell culture. Thus, the cellular morphology transition was monitored and analyzed numerically.

Cell morphology itself is recognized as a biological marker. The morphology of neural cells is quite important to cellular

Fig. 6. Analysis of cell morphology using phase contrast images of live cells. (A) Flow chart of phase contrast image-processing algorithm. Phase contrast images were processed to segment whole-cell regions (whole-cell region mask, orange) and elongated single-cell regions (Mask3, magenta). Mask1 (purple) was created by detecting cell-dense regions in the whole-cell region. Mask2 (green) was created by subtracting the Mask 1 region from the whole-cell region. Areas of Mask1, Mask2 and Mask3 were measured. (B) Representative processed images from Mask1 (purple), Mask2 (green), and Mask3 (magenta). NESTIN immunostaining (green) and nuclear staining (blue) of the fixed cell samples are shown for comparison with the phase contrast (live) image and the processed image. (C) Changes in the cell coverage areas of Mask1 (purple), Mask2 (green), and Mask3 (magenta) from days 0 to 8 (from 6 to 192 hours after seeding) during NELC induction. Measured results within the analyzed area $\left(11,075,584 \mu m^{2}, 3.33\right.$ $x 3.33 \mathrm{~mm}$ ) are shown. Black arrows in the graph panel indicate timing of medium change. 
development and the function of these cells (Kelava and Lancaster, 2016, Parekh and Ascoli, 2013). The cell morphology transition during in vitro differentiation also provides valuable information because cell differentiation is a continuous phenomenon. In this study, we found that EMT occurred during NELC induction from hPSCs by monitoring the cellular morphology of the cultured cells. EMT is the morphological transition process by which epithelial cells become mesenchymal cells (Thiery et al., 2009). Epithelial cells, which display a square shape, change into mesenchymal cells, which elongate and migrate outwards. In early embryogenesis, EMT plays crucial roles in the differentiation of multiple tissues and organs and the formation of a body plan (Thiery et al., 2009). During the EMT process, E-cadherin expression is down-regulated and SNAIL, SLUG, TWIST1, and VIMENTIN expression are induced (Kinehara et al., 2014, Thiery et al., 2009). In the present study, cells that had been cultured for 5 days, the time at which cells migrated out and exhibited morphological alterations, expressed these EMT-related genes. Under this condition, it is considered that TWIST leads EMT phenomena independently in different pathway from SNAIL (Kang et al., 2005), because up-regulation of SNAIL are impaired by GF 109203X (Kinehara et al., 2014). In addition to down-regulation of E-CAD and loss of E-CAD mediated cell-cell adhesion, acquisition of mesenchymal functions, particularly migratory function, initiates EMT and keeps cells in EMT state (Kang et al., 2005, Thiery et al., 2009). TWIST and other EMT-related genes including SLUG, VIMENTIN and N-CAD might play roles in the EMT events during NELC induction. The ability to monitor the cell morphology transition with time-lapse live-cell imaging provided valuable information about the mechanisms underlying differentiation.

We previously reported a non-invasive morphological analysis of hPSCs for classification of cell biological features, counting cell numbers and calculation of growth rate, measured from cell images (Kato et al., 2016, Suga et al., 2015). Based on these fundamental techniques, we quantified cell morphology during NELC induction from hPSCs. Time-lapse imaging revealed that the cells changed their shape and extended protrusions on days 5-6. We successfully report the ability to monitor differentiating cells and analyze the cellular transition using phase contrast imaging.

The medium which we developed for NELC induction in this study includes insulin, FGF-2 and heparan sulfate which enhances FGF-2 activity as a cofactor for FGF-2, but excludes transferrin, and BSA. The medium also contains SB431542 and GF 109203X with / without Dorsomorphin. We previously reported that FGF-2 induces activation of extracellular signal-regulated kinase-1/2 (ERK-1/2), phosphatidylinositol-3 kinase (PI3K) and also protein kinase C (PKC) pathways in hPSCs (Kinehara 2013). Inhibition of PKC pathway by GF 109203X supports PI3K/AKT signaling under FGF-2 signal pathway is also considered to contribute on cell survival without using ROCK inhibitor or albumin (Kinehara et al., 2014, Kinehara et al., 2013, Na et al., 2010). Neural linage differentiation of hPSCs is promoted by ERK1/2 signal pathway activated by FGF-2 (Chambers et al., 2009, Na et al., 2010). On the other hand, Dual inhibition of SMAD signaling using SB431542 and Noggin/Dorsomorphin is well-known to inhibit mesendoderm and extraembryonic differentiation of hPSCs cultured in the presence of knock-out serum replacement (KSR) and then promote the commitment into neural linage (Chambers et al., 2009). Because knock-out serum replacement which has BMP-like activity (Ying et al., 2003) is not included in our conditions, Dorsomorphin may not be required for the NELC induction. Considering that addition of Dorsomorphin supported the reproducible neural induction, autocrine BMP signaling (Dalton, 2013, Sakaki-Yumoto et al., 2013) might be expressed in the cells. Whether Noggin/ Dorsomorphin is truly required for the NELC induction should be determined in future. An accurate analysis was performed in chemically defined culture conditions to examine the effects of added factors. As shown in our previous study, heparan sulfate promotes FGF-2 activity in undifferentiated hESCs grown in a growth factor-defined culture medium, hESF9 (Furue et al., 2008). We screened a kinase inhibitor library to obtain a better understanding of FGF2-related molecular mechanisms regulating the self-renewal of hPSCs using hESF9 (Kinehara et al., 2013). Minimum essential culture conditions provide an experimental system suitable for elucidating the developmental responses to specific environmental stimuli, chemicals or drugs. The result in this study showed that the induced NELCs could differentiate into neurons with long, TUJ1-positive neurites and synapsin 1 (SYN1)-positive synaptic puncta. We also once tested the differentiation potential to glial cells, implying that they has a potential to differentiate into glial linage (data not shown). Using our new low-cell-density monolayer culture condition and non-invasive imaging technique, we are now planning to develop methods for analyzing diverse cellular phenomena in differentiating neural cells and their responses to extracellular compounds, such as growth factors, small-molecule inhibitors and agonists. The behavior, morphology and niche of individual cells should be accurately analyzed at each developmental stage to obtain an understanding of cellular phenomena during embryonic development.

Live-cell imaging based on fluorescent labeling with a fluorescent dye, immunostaining or exogenous gene expression is useful to track the expression of specific molecules (Hilderbrand, 2010, Kinehara et al., 2014, Kumagai et al., 2016, Suga et al., 2015). Specific target molecules are examined, and cells are subjected to some treatment; however, treated cells are not able to be used for further experiments or other purposes. In contrast, non-invasive live-cell imaging does not require cells to be treated (Kato et al., 2016, Suga et al., 2015). Our NELC induction method represents a potentially useful tool as a part of in vitro culture models for studying developmental biology.

\section{Materials and Methods}

\section{Cell lines}

An human ES cell (hESC) line H9 (Thomson et al., 1998) (WiCell, WI, USA, WA09) and an human induced pluripotent cell (hiPSC) line Tic (Nagata et al., 2009) (JCRB cell bank, Osaka, Japan, JCRB1331) were maintained on plates coated with bovine fibronectin (Sigma-Aldrich, $\mathrm{MO}$, USA) in growth factor-defined serum-free medium, hESF-FX, at $37^{\circ} \mathrm{C}$ in a $10 \% \mathrm{CO}_{2}$ atmosphere, as previously described (Furue et al., 2008, Kumagai et al., 2016, Yanagihara et al., 2016). Cultures of hESCs and hiPSCs were routinely passaged in clumps at 5- to 7-day intervals using Dispase II (Roche Life Science, Manheim, Germany). These cell lines were used in experiments within 20 passages (approximately 5 months) after they were obtained from the cell banks. The hESCs were used according to the guidelines for the utilization of hESCs of the Ministry of Education, Culture, Sports, Science and Technology of Japan. All experiments using hESCs and hiPSCs were conducted in the National Institutes of Biomedical Innovation, Health and Nutrition (NIBIOHN) with the approval of the Institutional Review Board of the NIBIOHN. 


\section{Cell culture media}

The hPSC maintenance medium, hESF-FX, was composed of mESF basal medium (Wako Pure Chemical, Osaka, Japan) supplemented with 2-aminoethanol (10 $\mu \mathrm{M}$, Sigma-Aldrich), 2-mercaptoethanol (10 $\mu \mathrm{M}$, Sigma-Aldrich), sodium selenite (20 nM, Sigma-Aldrich), human apotransferrin $(5 \mathrm{mg} / \mathrm{ml}$, Sigma-Aldrich), human recombinant insulin $(10 \mu \mathrm{g} /$ $\mathrm{ml}$, Sigma-Aldrich), L-ascorbic acid-2-phosphate $(0.1 \mathrm{mg} / \mathrm{ml}$, Wako), human recombinant FGF-2 (5 ng/ml, Katayama Chemical, Japan), and recombinant albumin ( $1 \mathrm{mg} / \mathrm{ml}$, Sigma-Aldrich) conjugated with oleic acid (9.4 ng/ml, Sigma-Aldrich). Human recombinant activin A (2 ng/ml, R\&D Systems, MN, USA) was added to hESF-FX when cells were passaged.

The plating medium for neuroepithelial-like cell (NELC) differentiation, ESF-NS1, was composed of mESF basal medium supplemented with sodium selenite $(20 \mathrm{nM})$, human recombinant insulin $(10 \mu \mathrm{g} / \mathrm{ml})$, L-ascorbic acid-2-phosphate $(0.1 \mathrm{mg} / \mathrm{ml})$, and human recombinant FGF-2 $(10 \mathrm{ng} / \mathrm{ml})$.

The induction medium for NELC differentiation, ESF-NS2(+), was composed of mESF basal medium supplemented with sodium selenite (20 $\mathrm{nM})$, human recombinant insulin $(10 \mu \mathrm{g} / \mathrm{ml})$, human recombinant FGF-2 (10 ng/ml), bovine heparan sulfate sodium salt (100 ng/ml, Sigma-Aldrich), SB431542 (10 $\mu \mathrm{M}$, Tocris Bioscience, UK), GF 109203X (2.5 $\mu \mathrm{M}$, Tocris Bioscience), and dorsomorphin (600 nM, Wako).

\section{Plate preparation for NELC induction}

Six-well tissue culture plates (Sumitomo Bakelite, Tokyo, Japan) were coated with poly-L-lysine (final concentration $40 \mathrm{ng} / \mathrm{ml}$, Sigma-Aldrich) for 30 minutes at room temperature and then with bovine fibronectin $(1 \mu \mathrm{g} /$ $\mathrm{cm}^{2}$, Sigma-Aldrich) for 3 hours at $37^{\circ} \mathrm{C}$.

\section{NELC induction}

Undifferentiated hPSCs maintained in hESF-FX medium were dissociated into single cells by treatment with Accutase (Merck Millipore, Darmstadt, Germany) for 4 minutes at $37^{\circ} \mathrm{C}$. Cells were suspended in ESF-NS1 medium and plated on a 6-well tissue culture plate coated with poly-L-lysine and bovine fibronectin at an appropriate cell density for each cell line (Tic: 2,400 cells $/ \mathrm{cm}^{2} ; \mathrm{H} 9: 6,000$ cells $/ \mathrm{cm}^{2}$ ). The plated cells were cultured at $37^{\circ} \mathrm{C}$ in a $10 \% \mathrm{CO}_{2}$ atmosphere, and the culture medium was replaced with ESF-NS2(+) on days 2 and 5.

\section{Immunocytochemistry}

Cells were fixed with $4 \%$ paraformaldehyde (Wako), followed by immunocytochemical staining using a previously described method (Kinehara et al., 2013). Primary antibodies against NESTIN (Merck Millipore), SOX2 (R\&D Systems), SOX1 (R\&D Systems), PAX6 (Covance, MA, USA), TUJ1 (tubulin $\beta 3$, Covance), SYN1 (synapsin 1, Merck Millipore) were used in this study. Nuclei were stained with Hoechst 33342 (Thermo Fisher Scientific, MA, USA). The fluorescence and phase contrast images were obtained using an ECLIPSE Ti microscope system (Nikon, Tokyo, Japan).

\section{Live-cell imaging}

Phase contrast time-lapse images of live cells were automatically acquired at $4 \mathrm{x}$ magnification and $2 \mu \mathrm{m}$ resolution per pixel in a culture observation system (BioStation CT, Nikon). The acquired images were analyzed using the image processing functions of CL-Quant software ver. 3.3 (Nikon). The scheme of image processing used in this study are described in Fig. 6A and Supplementary Table S2.

\section{Neuronal differentiation}

The induced NELCs were harvested with Accutase on day 8 and re-plated in ESF-NS2 medium supplemented with L-ascorbic acid-2-phosphate $(0.1$ $\mathrm{mg} / \mathrm{ml}$ ) on a 24-well plate (BD Biosciences, NJ, USA) coated with mouse laminin $\left(2.5 \mu \mathrm{g} / \mathrm{cm}^{2}\right.$, Merck Millipore) at a density of $40,000 \mathrm{cells} / \mathrm{cm}^{2}$. Two days after re-plating, the culture medium was replaced with neuronal differentiation medium (Brewer et al., 1993): Neurobasal-A medium supplemented with B-27 supplement minus vitamin A, an MEM non-essential amino acids solution, and Gluta-MAX supplement (all from Gibco, Thermo
Fisher Scientific, MA, USA). The culture medium was replaced every 3-4 days. The differentiated cells were fixed on day 20 after re-plating.

\section{Quantitative real-time PCR}

Total RNA was extracted from undifferentiated hPSCs or hPSC-derived NELCs using AllPrep DNA/RNA Mini kits (Qiagen, Germany), treated with RNase-free DNase I (Invitrogen Thermo Fisher Scientific, MA, USA), and reverse transcribed with SuperScript VILO cDNA synthesis kits (Invitrogen), according to the manufacturer's instructions. Synthesized cDNAs were amplified using gene-specific primers (Invitrogen), which are listed in Supplementary Table S1.

\section{Acknowledgments}

This study was partially supported by grants-in-aid from the Ministry of Health, Labour and Welfare of Japan; the Japan Agency for Medical Research and Development (AMED) to M.K.F. (JP17bk0104011h0005); the Ministry of Education, Culture, Sports, Science and Technology of Japan to M.K.F. and M.S. (KAKEN 15K11035 and 16H05535); and Nikon Corporation as a collaboration research with NIBIOHN to M.K.F.

\section{References}

BREWER, G.J., TORRICELLI, J.R., EVEGE, E.K. and PRICE, P.J. (1993). Optimized survival of hippocampal neurons in B27-supplemented Neurobasal, a new serumfree medium combination. J Neurosci Res 35: 567-576.

CHAMBERS, S.M., FASANO, C.A., PAPAPETROU, E.P., TOMISHIMA, M., SADELAIN M. and STUDER, L. (2009). Highly efficient neural conversion of human ES and iPS cells by dual inhibition of SMAD signaling. Nature Biotech. 27: 275-280.

DALTON, S. (2013). Signaling networks in human pluripotent stem cells. Curr Opin Cell Biol 25: 241-246.

DERYCKE, L.D. and BRACKE, M.E. (2004). N-cadherin in the spotlight of cell-cell adhesion, differentiation, embryogenesis, invasion and signalling. Int J Dev Biol 48: 463-476.

FAVATA, M.F., HORIUCHI, K.Y., MANOS, E.J., DAULERIO, A.J., STRADLEY, D.A., FEESER, W.S., VAN DYK, D.E., PITTS, W.J., EARL, R.A., HOBBS, F. et al., (1998). Identification of a novel inhibitor of mitogen-activated protein kinase kinase. J Biol Chem 273: 18623-18632.

FLAUMENHAFT, R., MOSCATELLI, D. and RIFKIN, D.B. (1990). Heparin and heparan sulfate increase the radius of diffusion and action of basic fibroblast growth factor. J Cell Biol 111: 1651-1659.

FUKUI, A. and ASASHIMA, M. (1994). Control of cell differentiation and morphogenesis in amphibian development. Int J Dev Biol 38: 257-266.

FURUE, M. and ASASHIMA, M. (2004). 46. Isolation of pluripotential stem cells from Xenopus embryos. In Handbook of stem cells, vol. Vol.1 Embryonic Stem Cells. (ed. LANZA, R.). Academic Press, San Diego, pp.483-492.

FURUE, M., OKAMOTO, T., HAYASHI, Y., OKOCHI, H., FUJIMOTO, M., MYOISHI, Y., ABE, T., OHNUMA, K., SATO, G.H., ASASHIMA, M. et al., (2005). Leukemia inhibitory factor as an anti-apoptotic mitogen for pluripotent mouse embryonic stem cells in a serum-free medium without feeder cells. In Vitro Cell Dev Biol Anim 41: 19-28.

FURUE, M., OKAMOTO, T., IKEDA, M., TANAKA, Y., SASAKI, Y., NISHIHIRA, K. and SATO, J.D. (1994). Primitive neuroectodermal tumor cell lines derived from a metastatic pediatric tumor. In Vitro Cell Dev Biol Anim 30A: 813-816.

FURUE, M.K., NA, J., JACKSON, J.P., OKAMOTO, T., JONES, M., BAKER, D., HATA, R., MOORE, H.D., SATO, J.D. and ANDREWS, P.W. (2008). Heparin promotes the growth of human embryonic stem cells in a defined serum-free medium. Proc Natl Acad Sci USA 105: 13409-13414.

HAYASHI, Y., FURUE, M.K., TANAKA, S., HIROSE, M., WAKISAKA, N., DANNO, H. OHNUMA, K., OEDA, S., AIHARA, Y., SHIOTA, K. et al., (2010). BMP4 induction of trophoblast from mouse embryonic stem cells in defined culture conditions on laminin. In Vitro Cell Dev Biol Anim 46: 416-430.

HERS, I., TAVARE, J.M. and DENTON, R.M. (1999). The protein kinase C inhibitors bisindolylmaleimide I (GF 109203x) and IX (Ro 31-8220) are potent inhibitors of glycogen synthase kinase-3 activity. FEBS Lett 460: 433-436.

HILDERBRAND, S.A. (2010). Labels and probes for live cell imaging: overview and selection guide. Methods Mol Biol 591: 17-45. 
INMAN, G.J. (2002). SB-431542 is a potent and specific inhibitor of transforming growth factor-[bgr] superfamily type I activin receptor-like kinase (ALK) receptors ALK4, ALK5, and ALK7. Mol. Pharmacol. 62: 65-74.

KANG, Y., HE, W., TULLEY, S., GUPTA, G.P., SERGANOVA, I., CHEN, C.-R., MANOVA-TODOROVA, K., BLASBERG, R., GERALD, W.L. and MASSAGU, J. (2005). Breast cancer bone metastasis mediated by the Smad tumor suppressor pathway. Proc Natl Acad Sci USA 102: 13909-13914.

KATO, R., MATSUMOTO, M., SASAKI, H., JOTO, R., OKADA, M., IKEDA, Y., KANIE, K., SUGA, M., KINEHARA, M., YANAGIHARA, K. et al., (2016). Parametric analysis of colony morphology of non-labelled live human pluripotent stem cells for cell quality control. Sci Rep 6: 34009.

KELAVA, I. and LANCASTER, MADELINE A. (2016). Stem Cell Models of Human Brain Development. Cell Stem Cell 18: 736-748.

KINEHARA, M., KAWAMURA, S., MIMURA, S., SUGA, M., HAMADA, A., WAKABAYASHI, M., NIKAWA, H. and FURUE, M.K. (2014). Protein kinase C-induced early growth response protein-1 binding to SNAIL promoter in epithelial-mesenchymal transition of human embryonic stem cells. Stem Cells Dev 23: 2180-2189.

KINEHARA, M., KAWAMURA, S., TATEYAMA, D., SUGA, M., MATSUMURA, H., MIMURA, S., HIRAYAMA, N., HIRATA, M., UCHIO-YAMADA, K., KOHARA, A. et al., (2013). Protein kinase $C$ regulates human pluripotent stem cell self-renewal. PLoS One 8: e54122.

KUMAGAI, A., SUGA, M., YANAGIHARA, K., ITOH, Y., TAKEMORI, H. and FURUE, M.K. (2016). ASimple Method for Labeling Human Embryonic Stem Cells Destined to Lose Undifferentiated Potency. Stem Cells Transl Med 5: 275-281.

LAMOUILLE, S., XU, J. and DERYNCK, R. (2014). Molecular mechanisms of epithelialmesenchymal transition. Nat Rev Mol Cell Biol 15: 178-196.

MADDAH, M., SHOUKAT-MUMTAZ, U., NASSIRPOUR, S. and LOEWKE, K. (2014). A system for automated, noninvasive, morphology-based evaluation of induced pluripotent stem cell cultures. J Lab Autom 19: 454-460.

NA, J., FURUE, M.K. and ANDREWS, P.W. (2010). Inhibition of ERK1/2 prevents neural and mesendodermal differentiation and promotes human embryonic stem cell self-renewal. Stem Cell Res 5: 157-169.

NAGATA, S., TOYODA, M., YAMAGUCHI, S., HIRANO, K., MAKINO, H., NISHINO, K., MIYAGAWA, Y., OKITA, H., KIYOKAWA, N., NAKAGAWA, M. et al., (2009). Efficient reprogramming of human and mouse primary extra-embryonic cells to pluripotent stem cells. Genes Cells 14: 1395-1404.

PAREKH, R. and ASCOLI, GIORGIO A. (2013). Neuronal Morphology Goes Digital:
A Research Hub for Cellular and System Neuroscience. Neuron 77: 1017-1038.

SAKAKI-YUMOTO, M., LIU, J., RAMALHO-SANTOS, M., YOSHIDA, N. and DERYNCK R. (2013). Smad2 Is Essential for Maintenance of the Human and Mouse Primed Pluripotent Stem Cell State. J. Biol. Chem. 288: 18546-18560.

SUGA, M., KII, H., NIIKURA, K., KIYOTA, Y. and FURUE, M.K. (2015). Development of a Monitoring Method for Nonlabeled Human Pluripotent Stem Cell Growth by Time-Lapse Image Analysis. Stem Cells Transl Med 4: 720-730.

TAKAHASHI, K., TANABE, K., OHNUKI, M., NARITA, M., ICHISAKA, T., TOMODA, K and YAMANAKA, S. (2007). Induction of pluripotent stem cells from adult human fibroblasts by defined factors. Cell 131: 861-872.

THIERY, J.P., ACLOQUE, H., HUANG, R.Y. and NIETO, M.A. (2009). Epithelialmesenchymal transitions in development and disease. Cell 139: 871-890.

THOMSON, J.A., ITSKOVITZ-ELDOR, J., SHAPIRO, S.S., WAKNITZ, M.A., SWIERGIEL, J.J., MARSHALL, V.S. and JONES, J.M. (1998). Embryonic stem cell lines derived from human blastocysts. Science 282: 1145-1147.

VALENZUELA, D.M., ECONOMIDES, A.N., ROJAS, E., LAMB, T.M., NUNEZ, L., JONES, P., LP, N.Y., ESPINOSA, R., 3RD, BRANNAN, C.I., GILBERT, D.J. et al., (1995). Identification of mammalian noggin and its expression in the adult nervous system. J Neurosci 15: 6077-6084.

VALLIER, L., TOUBOUL, T., BROWN, S., CHO, C., BILICAN, B., ALEXANDER, M. CEDERVALL, J., CHANDRAN, S., AHRLUND-RICHTER, L., WEBER, A. et al., (2009). Signaling pathways controlling pluripotency and early cell fate decisions of human induced pluripotent stem cells. Stem Cells 27: 2655-2666.

VLAHOS, C.J., MATTER, W.F., HUI, K.Y. and BROWN, R.F. (1994). A specific inhibitor of phosphatidylinositol 3-kinase, 2-(4-morpholinyl)-8-phenyl-4H-1-benzopyran4-one (LY294002). J Biol Chem 269: 5241-5248.

YANAGIHARA, K., LIU, Y., KANIE, K., TAKAYAMA, K., KOKUNUGI, M., HIRATA M., FUKUDA, T., SUGA, M., NIKAWA, H., MIZUGUCHI, H. et al., (2016). Prediction of Differentiation Tendency Toward Hepatocytes from Gene Expression in Undifferentiated Human Pluripotent Stem Cells. Stem Cells Dev 25: 1884-1897.

YING, Q.L., NICHOLS, J., CHAMBERS, I. and SMITH, A. (2003). BMP induction of Id proteins suppresses differentiation and sustains embryonic stem cell self-renewa in collaboration with STAT3. Cell 115: 281-292.

YU, J., HU, K., SMUGA-OTTO, K., TIAN, S., STEWART, R., SLUKVIN, II and THOMSON, J.A. (2009). Human induced pluripotent stem cells free of vector and transgene sequences. Science 324: 797-801. 


\section{Further Related Reading, published previously in the Int. J. Dev. Biol.}

Pluripotent human stem cells: Standing on the shoulders of giants

Ivan Damjanov and Peter W Andrews

Int. J. Dev. Biol. (2016) 60: 321-325

https://doi.org/10.1387/ijdb.160437id

Generation of pluripotent stem cells via protein transduction

Xia Li, Pengfei Zhang, Chao Wei and Yunhai Zhang

Int. J. Dev. Biol. (2014) 58: 21-27

https://doi.org/10.1387/ijdb.140007XL

Testicular teratomas: an intersection of pluripotency, differentiation and cancer biology

Ximena Bustamante-Marín, Jason A. Garness and Blanche Capel

Int. J. Dev. Biol. (2013) 57: 201-210

https://doi.org/10.1387/ijdb.130136bc

Long-term serial cultivation of mouse induced pluripotent stem cells in serum-free and feeder-free defined medium

Sachiko Yamasaki, Kou Nabeshima, Yusuke Sotomaru, Yuki Taguchi, Hanae Mukasa, Miho K. Furue, J. Denry Sato and Tetsuji Okamoto Int. J. Dev. Biol. (2013) 57: 715-724

https://doi.org/10.1387/ijdb.130173to

Novel roles for Notch, Wnt and Hedgehog in hematopoesis derived from human pluripotent stem cells

Chantal Cerdan and Mickie Bhatia

Int. J. Dev. Biol. (2010) 54: 955-964

https://doi.org/10.1387/ijdb.103067cc

Feeder- and serum-free establishment and expansion of human induced pluripotent stem cells

Mehdi Totonchi, Adeleh Taei, Ali Seifinejad, Mohammadsharif Tabebordbar, Hassan Rassouli, Ali Farrokhi, Hamid Gourabi, Nasser Aghdami, Ghasem Hosseini-Salekdeh and Hossein Baharvand

Int. J. Dev. Biol. (2010) 54: 877-886

https://doi.org/10.1387/ijdb.092903mt

Signaling pathways during maintenance and definitive endoderm differentiation of embryonic stem cells Lina Sui, Luc Bouwens and Josué K. Mfopou

Int. J. Dev. Biol. (2013) 57: 1-12

https://doi.org/10.1387/ijdb.120115ls

5 yr ISI Impact Factor $(2016)=2.421$

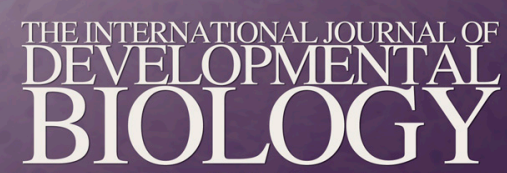

Volume 60 Nos. 10/11/12

Special Issue

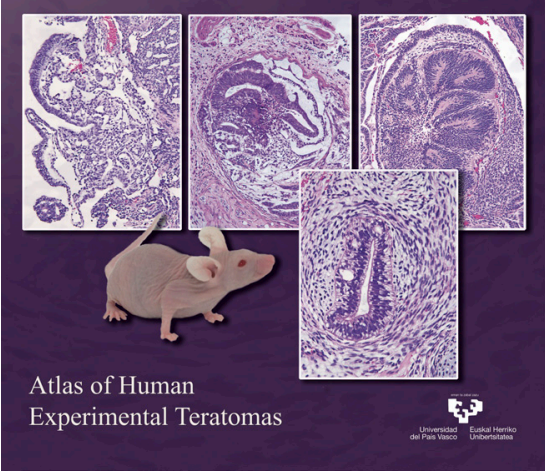

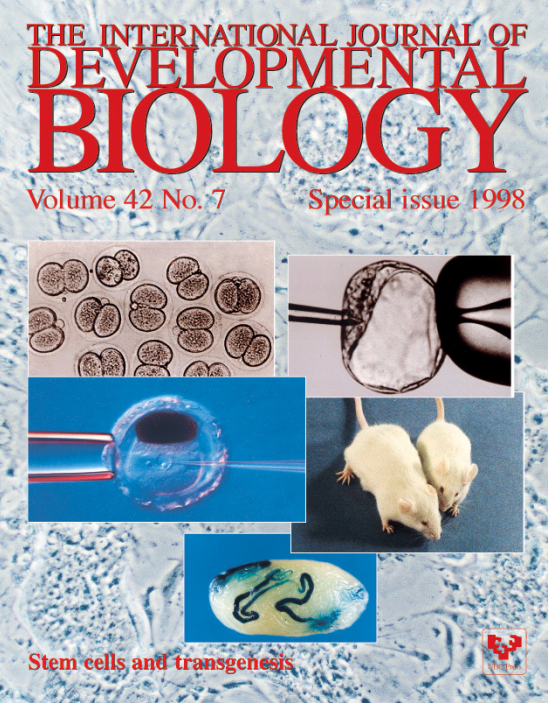

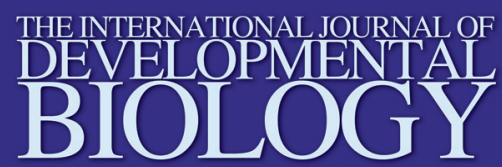

Volume 62 Nos. 6/7/8

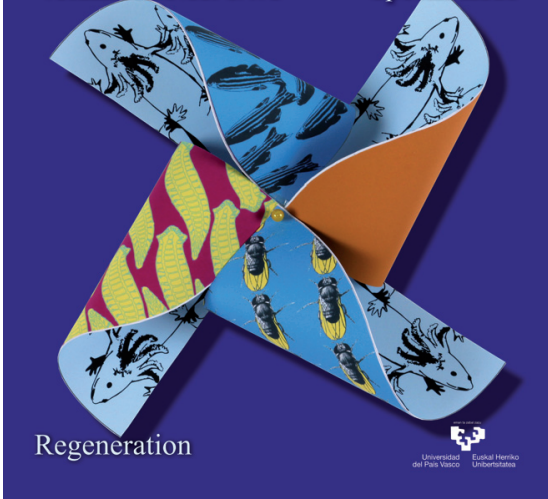

